Case Report

\title{
A Rare Case of Renal Recovery in a Young Patient with Multiple Myeloma
}

\author{
Hasan J. Salameh, Adeel Ahmad, and Tina Kochar \\ Department of Internal Medicine, University of Texas Medical Branch, Galveston, TX 77555-0562, USA \\ Correspondence should be addressed to Adeel Ahmad; adahmad@utmb.edu
}

Received 15 February 2013; Accepted 11 March 2013

Academic Editors: R. Enríquez, C. Goonasekera, and R. Kazancioglu

Copyright (C) 2013 Hasan J. Salameh et al. This is an open access article distributed under the Creative Commons Attribution License, which permits unrestricted use, distribution, and reproduction in any medium, provided the original work is properly cited.

Multiple myeloma (MM) is an uncommon hematologic malignancy accounting for $1 \%$ of all malignancies. Renal involvement is a common complication of MM. Rapid intervention to reverse renal dysfunction may be critical for management, especially in patients with light chain cast nephropathy. Recovery rate ranges from 5\% to $15 \%$. We describe an atypical presentation of MM in a young patient who presented with severe renal insufficiency requiring renal replacement therapy and achieved complete renal recovery with chemotherapy.

\section{Introduction}

Multiple myeloma (MM) is described as a hematologic malignancy characterized by the neoplastic proliferation of a single clone of plasma cells producing a monoclonal immunoglobulin. The most common location for this neoplastic proliferation is bone marrow, but extraskeletal disease is described as well. MM accounts for approximately $1 \%$ of all malignancies and $10 \%$ of all hematologic malignancies [1]. The annual incidence in the US is approximately from 4 to 5 per 100,000 [2]. MM occurs in all races and occurs in all geographic locations, but the incidence varies by ethnicity. African Americans are 2-3 times more likely than whites to develop MM [3, 4]. Asians and Mexicans both have a lower incidence than whites. MM is more frequent in men than in women (approximately $1.4: 1$ ) [5]. MM has been known to be a disease of older adults, where the median age at diagnosis is 66 years. Only 10 percent are younger than 50 years, and a mere 2 percent of patients are younger than 40 years $[6,7]$.

The most common signs and symptoms of MM are anemia, bone pain, abnormal renal function, fatigue, and hypercalcemia [6]. Often the diagnosis of MM results from a workup of unexplained renal disease due to the excessive production of light chains that accumulate in the kidneys causing damage. Renal disease is a common feature in MM, and it is estimated that a serum creatinine of $>1.3 \mathrm{mg} / \mathrm{dL}$ is present in approximately $50 \%$ of cases [6]. Severe renal insufficiency (serum creatinine $>2.5 \mathrm{mg} / \mathrm{dL}$ ) is seen in $15-$ $20 \%$ of cases [8]. Several studies have shown that renal lesions in patients with MM vary. Cast nephropathy was found in $40-60 \%, 19-26 \%$ had light-chain disease, $4-30 \%$ had amyloidosis, and $<1 \%$ had cryoglobulinemic renal disease [9]. It has been stated that the risk of renal failure is associated with the amount of light-chain excretion [10]. The presence and severity of renal insufficiency in patients with multiple myeloma is associated with poor prognosis in regards to both morbidity and mortality [10].

\section{Case Report}

A previously healthy, 31-year-old Caucasian male presented with complaints of abdominal pain radiating to the flanks, dark colored urine, and fatigue for the last 2 months. On physical examination, patient was noted to be afebrile, and his blood pressure was 130/84 mmHg. He had pale conjunctivae. The lungs were clear on auscultation, and no focal neurological deficit was found. Examination of the extremities revealed no pedal edema. Laboratory analysis revealed a normal white blood cell count, hemoglobin of $8.5 \mathrm{gm} / \mathrm{dL}$, serum blood urea nitrogen of $79 \mathrm{mg} / \mathrm{dL}$, creatinine of $22.5 \mathrm{mg} / \mathrm{dL}$, and total serum calcium of $11.2 \mathrm{mg} / \mathrm{dL}$. LDH was elevated at $1178 \mathrm{U} / \mathrm{L}$. Urinalysis was significant for $1+$ proteinuria, no 


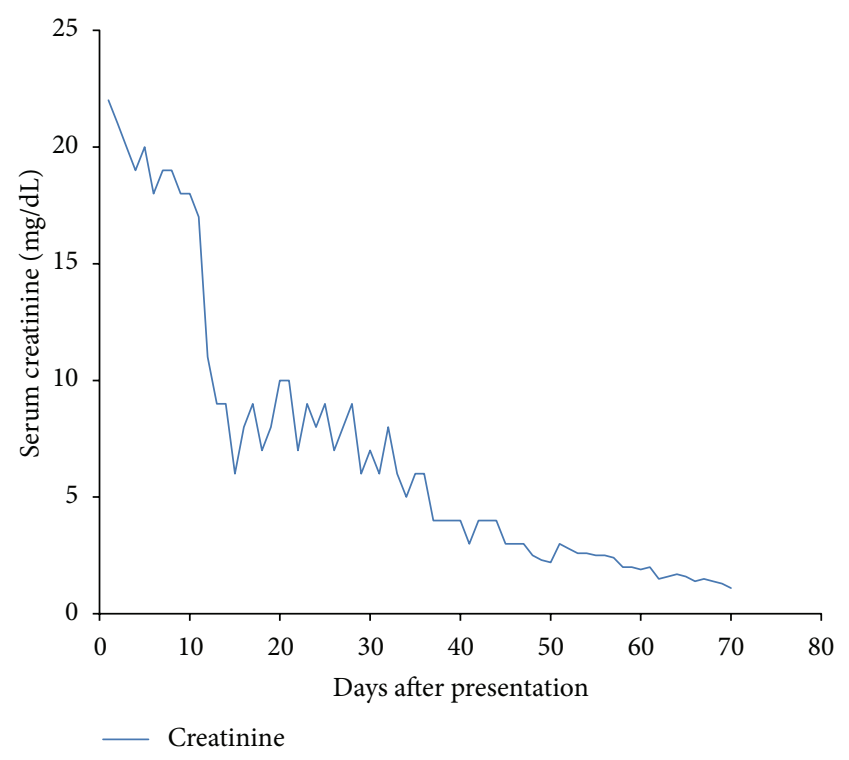

Figure 1: Serum Creatinine.

cast or crystals was visualized by urine microscopy. The spot urine protein/creatinine ratio was estimated at 2.4 grams per day. The computed tomography of abdomen and pelvis for evaluation of abdominal pain demonstrated diffuse lytic bone lesions, which prompted work-up for multiple myeloma. Serum protein electrophoresis did not show any M-spike. Urine immunoelectrophoresis revealed kappa light chains. Serum light chain assay revealed high kappa light chain at $931 \mathrm{mg} / \mathrm{dL}$ (normal 0.33-1.94 mg/dL). Lambda light chains were suppressed at $0.25 \mathrm{mg} / \mathrm{dL}$ (normal $0.57-2.63 \mathrm{mg} / \mathrm{dL}$ ). Bone marrow biopsy showed $60 \%-70 \%$ of bone marrow area was replaced by plasma cells. A kidney biopsy revealed cast nephropathy with strong staining of kappa light chain in tubular basement membrane on immunofluorescence. No electron dense deposits were seen on electron microscopy.

The patient was initiated on hemodialysis with standard high flux membrane (not high cut off membrane dialyzer) and received his first of 6 cycles of chemotherapy (bortezomib, doxorubicin, and dexamethasone). After the second cycle of chemotherapy, patient's renal function improved significantly, and he did not require further dialysis (Figure 1). He received a total 4 weeks of hemodialysis on a three times per week schedule. During his outpatient follow-up visits, the serum creatinine continued to improve, and by the last chemotherapy session, patient's serum creatinine was $1.4 \mathrm{mg} / \mathrm{dL}$. Patient's most recent creatinine is less than $1 \mathrm{mg} / \mathrm{dL}$.

\section{Discussion}

Presentation of MM may be different in younger patients. Younger patients present with more favorable features and have a better survival. Factors associated with improved survival include young males with low International Staging System (ISS) and Durie-Salmon stage, good performance status, and absence of poor prognostic features as high CRP, low hemoglobin, and severe renal insufficiency [11, 12].

Patients with previously normal renal function or mild renal insufficiency and patients with precipitating factors for renal disease (dehydration, NSAIDs use, and hypercalcemia) have better renal outcome [13]. Presence of renal insufficiency predicts poor survival. Patients presenting with serum creatinine of $<1.4 \mathrm{mg} / \mathrm{dL}$ had a mean survival of 44 months compared to 18 months for patients presenting with creatinine of $1.4-2.0 \mathrm{mg} / \mathrm{dL}$. Patients presenting with creatinine of $>2.0 \mathrm{mg} / \mathrm{dL}$ had mean survival of less than 4 months [14].

Our case illustrates complete or near complete recovery of GFR with chemotherapy in a young patient who presented with severe renal insufficiency. To our knowledge, there is no large study comparing renal survival in young versus old patients presenting with renal involvement of MM. The response to therapy in this young male may suggest a better prognosis for recovery of renal function in this age group.

\section{References}

[1] A. Jemal, R. Siegel, E. Ward, Y. Hao, J. Xu, and M. J. Thun, “Cancer statistics, 2009," CA Cancer Journal for Clinicians, vol. 59, no. 4, pp. 225-249, 2009.

[2] K. J. Phekoo, S. A. Schey, M. A. Richards et al., "A population study to define the incidence and survival of multiple myeloma in a National Health Service Region in UK," British Journal of Haematology, vol. 127, no. 3, pp. 299-304, 2004.

[3] S. Y. Huang, M. Yao, J. L. Tang et al., "Epidemiology of multiple myeloma in Taiwan: increasing incidence for the past 25 years and higher prevalence of extramedullary myeloma in patients younger than 55 years," Cancer, vol. 110, no. 4, pp. 896-905, 2007.

[4] R. A. Kyle, M. A. Gertz, T. E. Witzig et al., "Review of 1027 patients with newly diagnosed multiple myeloma," Mayo Clinic Proceedings, vol. 78, no. 1, pp. 21-33, 2003.

[5] J. Bladé and R. A. Kyle, "Multiple myeloma in young patients: clinical presentation and treatment approach," Leukemia and Lymphoma, vol. 30, no. 5-6, pp. 493-501, 1998.

[6] N. J. Camp, T. L. Werner, and L. A. Cannon-Albright, "Familial myeloma," The New England Journal of Medicine, vol. 359, no. 16, pp. 1734-1735, 2008.

[7] M. Jain, J. Ascensao, and G. P. Schechter, "Familial myeloma and monoclonal gammopathy: a report of eight African American families," American Journal of Hematology, vol. 84, no. 1, pp. 3438, 2009.

[8] L. M. Knudsen, E. Hippe, M. Hjorth, E. Holmberg, and J. Westin, "Renal function in newly diagnosed multiple myeloma-a demographic study of 1353 patients," European Journal of Haematology, vol. 53, no. 4, pp. 207-212, 1994.

[9] J. Bladé, P. Fernández-Llama, F. Bosch et al., "Renal failure in multiple myeloma: presenting features and predictors of outcome in 94 patients from a single institution," Archives of Internal Medicine, vol. 158, no. 17, pp. 1889-1893, 1998.

[10] S. M. Korbet and M. M. Schwartz, "Multiple myeloma," Journal of the American Society of Nephrology, vol. 17, no. 9, pp. 25332545, 2006.

[11] J. Bladé, R. A. Kyle, and P. R. Greipp, "Presenting features and prognosis in 72 patients with multiple myeloma who were younger than 40 years," British Journal of Haematology, vol. 93, no. 2, pp. 345-351, 1996. 
[12] A. Corso, C. Klersy, M. Lazzarino, and C. Bernasconi, "Multiple myeloma in younger patients: the role of age as prognostic factor," Annals of Hematology, vol. 76, no. 2, pp. 67-72, 1998.

[13] H. Ludwig, B. G. M. Durie, V. Bolejack et al., "Myeloma in patients younger than age 50 years presents with more favorable features and shows better survival: an analysis of 10549 patients from the International Myeloma Working Group," Blood, vol. 111, no. 8, pp. 4039-4047, 2008.

[14] H. C. Rayner, A. P. Haynes, J. R. Thompson, N. Russell, and J. Fletcher, "Perspectives in multiple myeloma: survival, prognostic factors and disease complications in a single centre between 1975 and 1988," Quarterly Journal of Medicine, vol. 79, no. 290, pp. 517-525, 1991. 


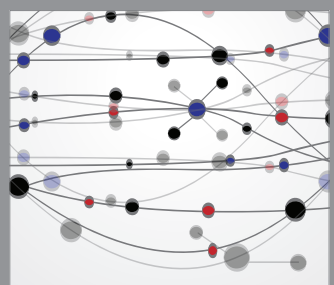

The Scientific World Journal
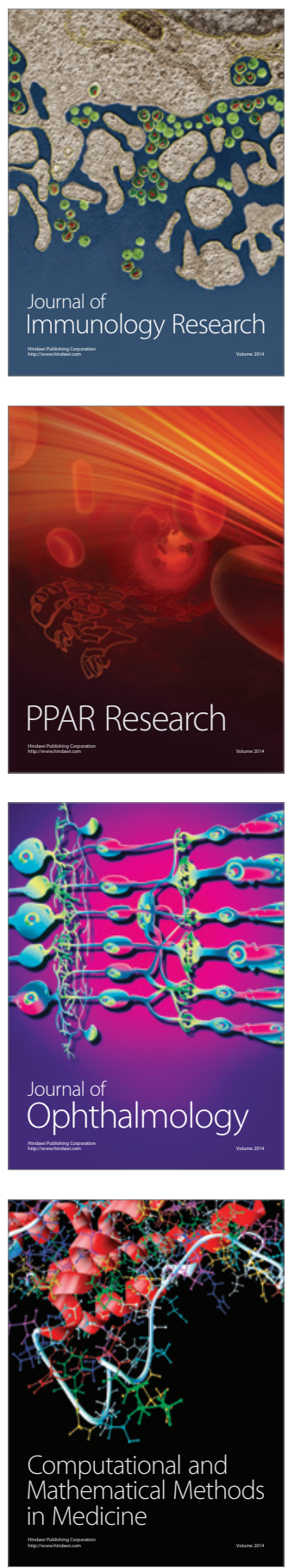

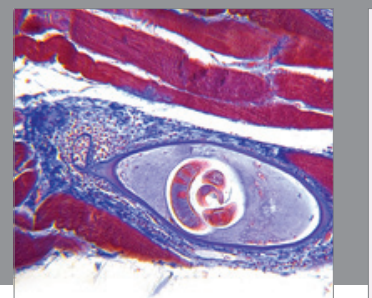

Gastroenterology

Research and Practice
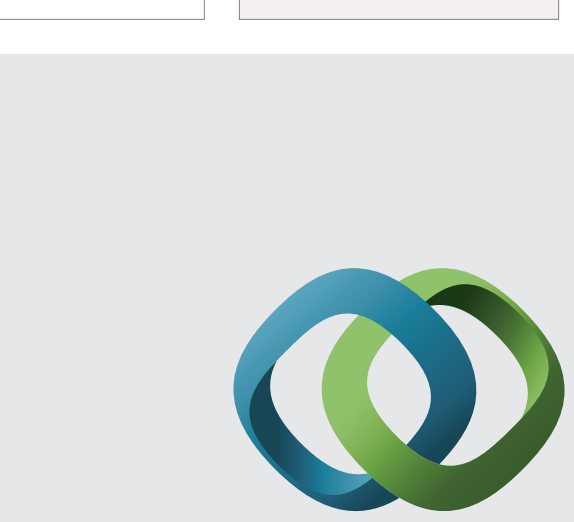

\section{Hindawi}

Submit your manuscripts at

http://www.hindawi.com
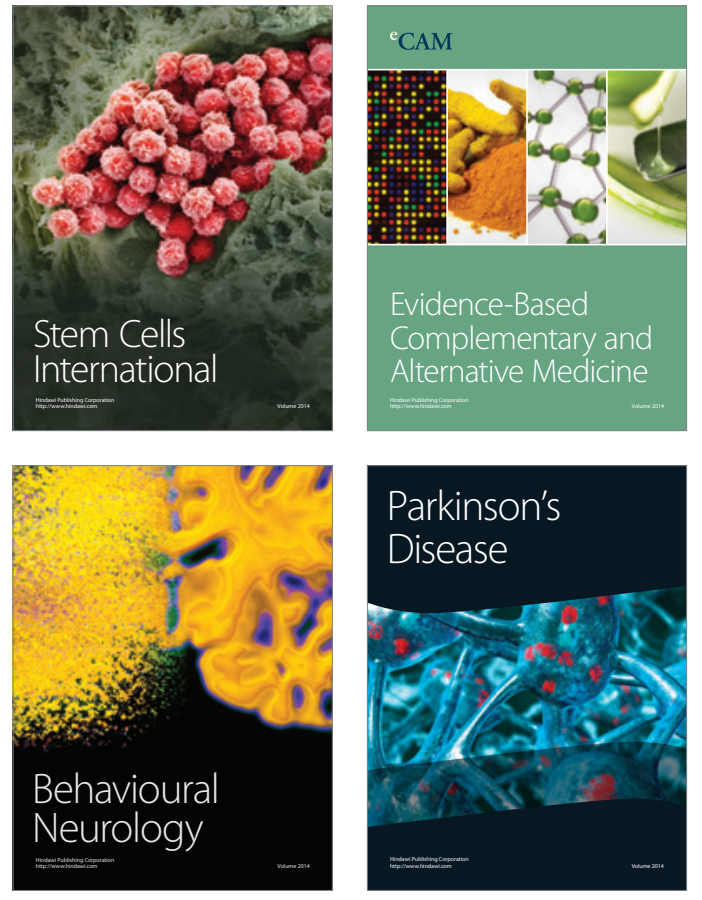
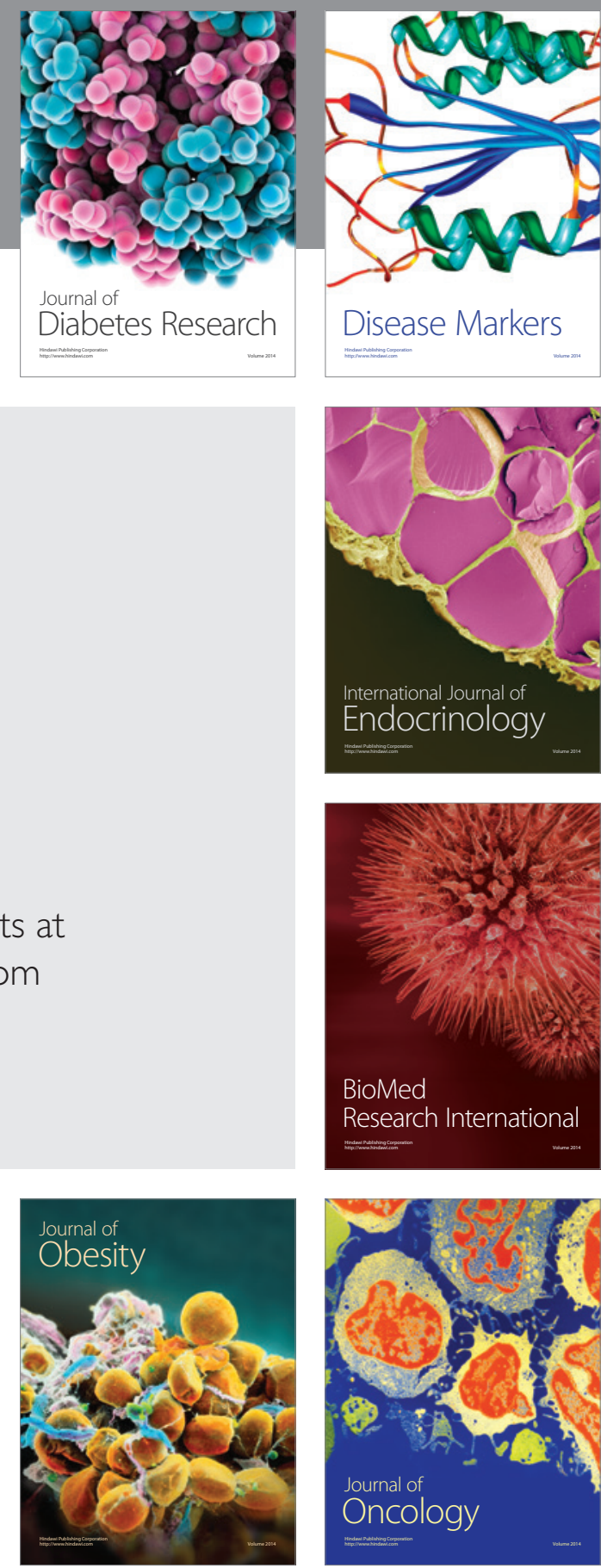

Disease Markers
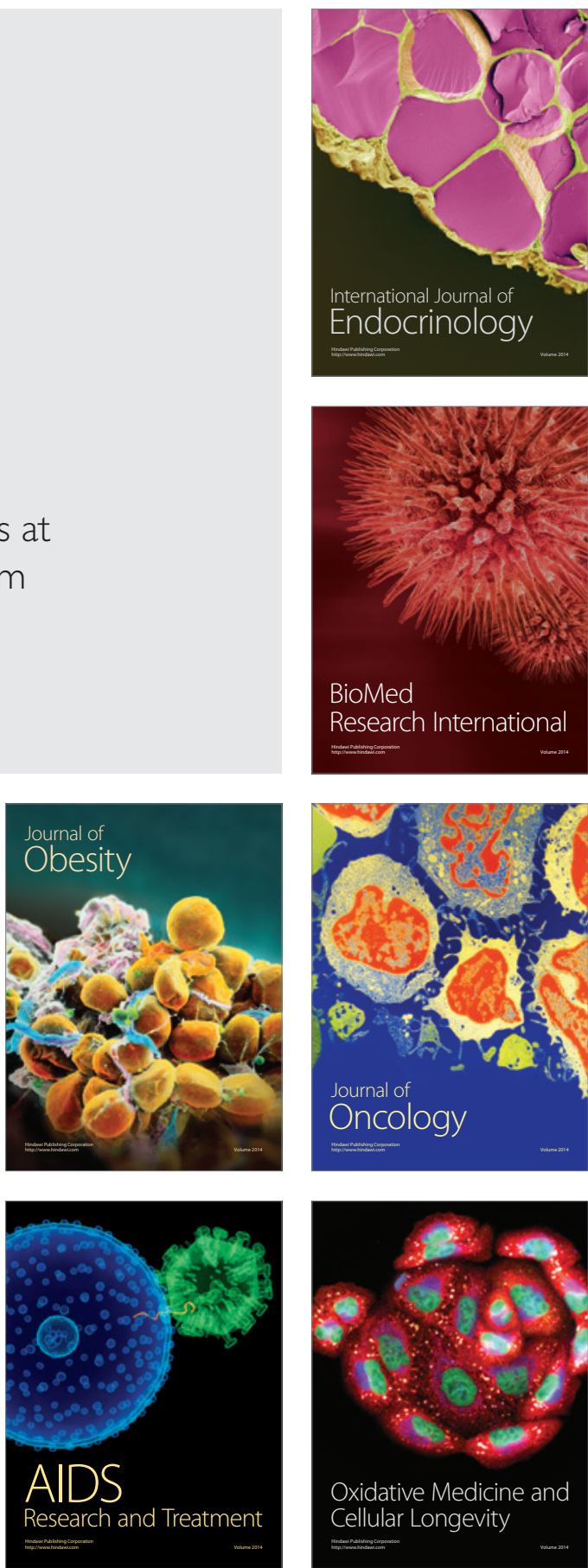